
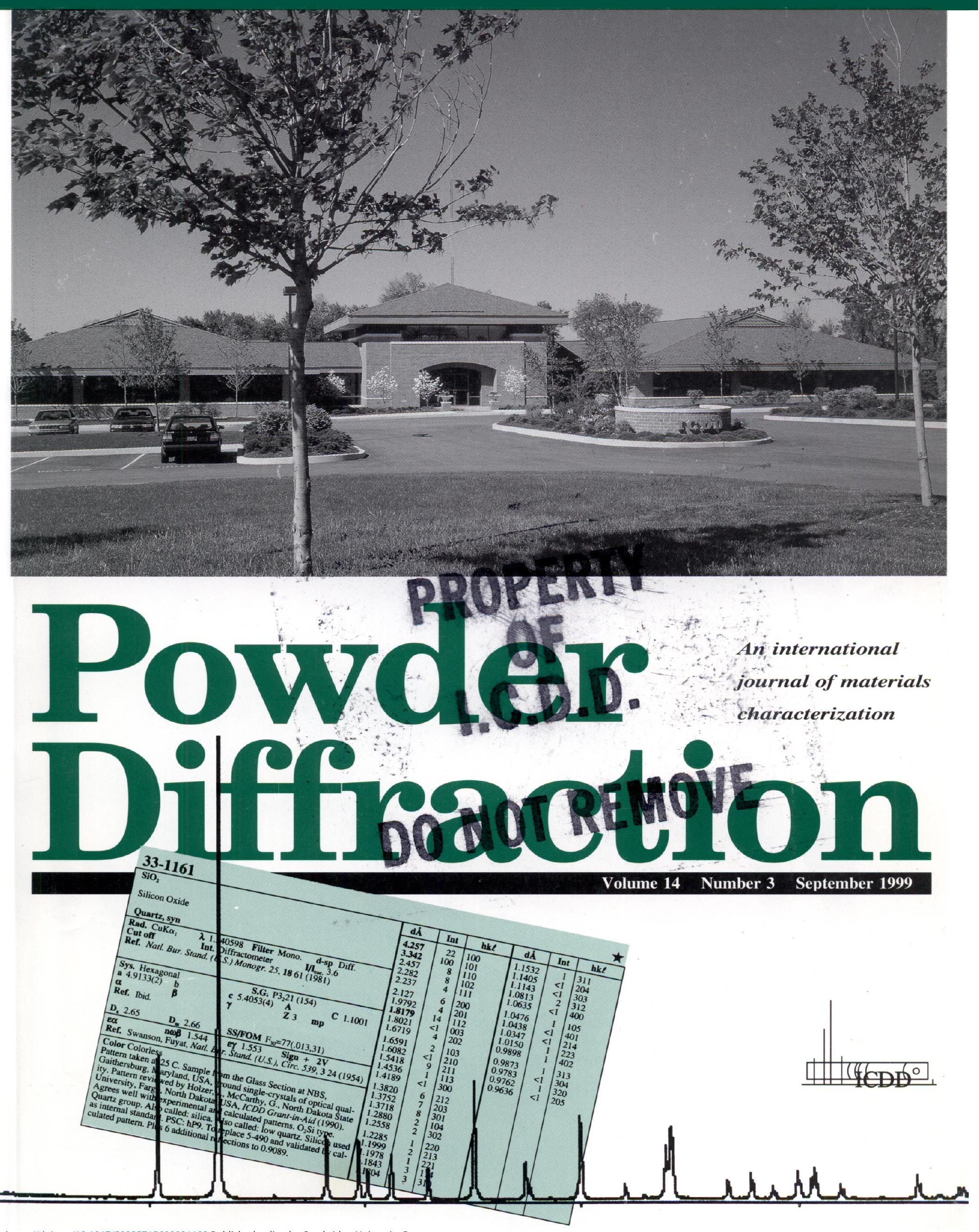


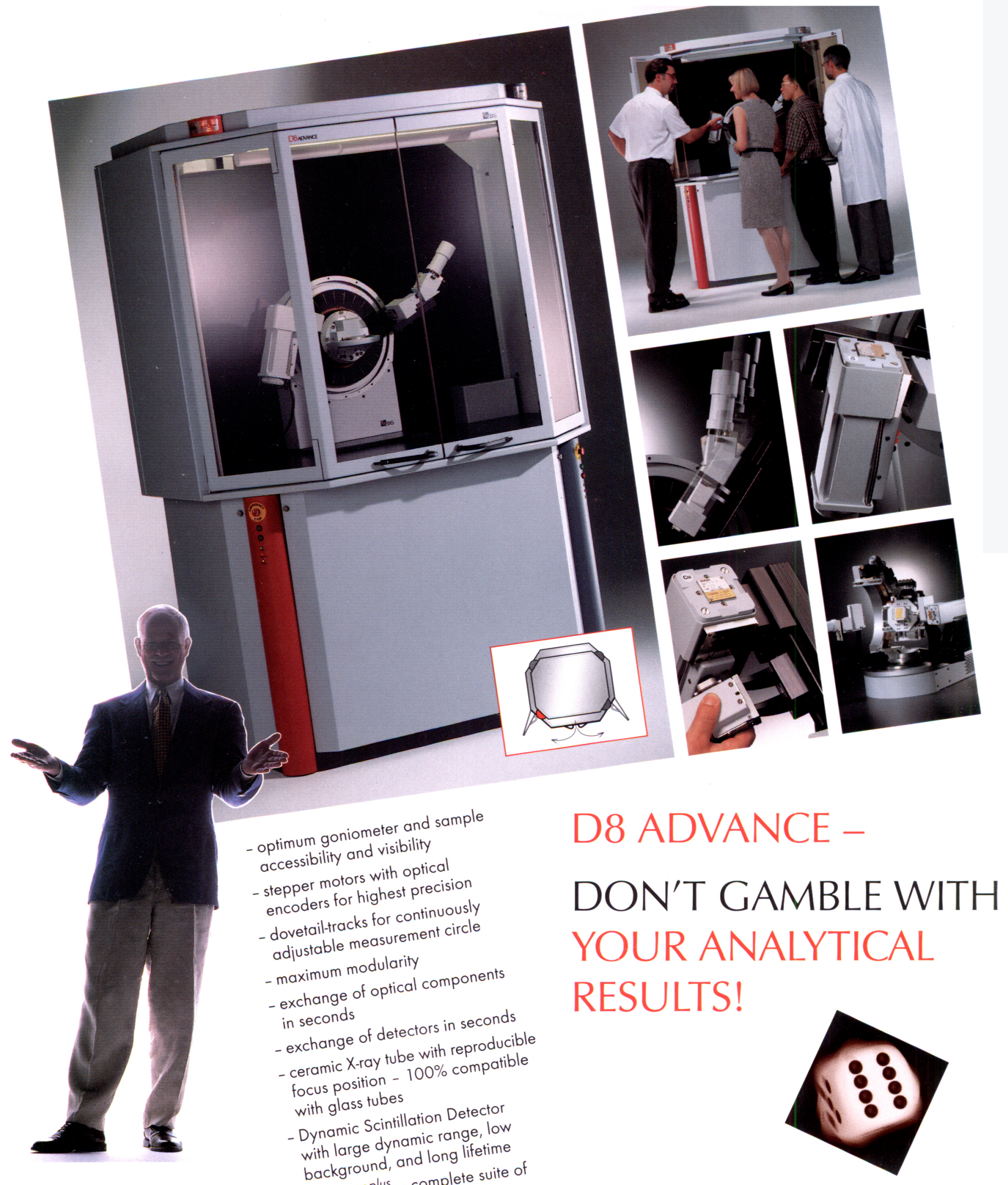




\section{crystallographica searchmatch}

The makers of Crystallographica are proud to announce the launch of Crystallographica Search-Match, an all-new search-match program for Windows 95/98/NT.

- Works with all versions of the Powder Diffraction File including the new CPDF

- Search using full powder diffraction pattern and/or peak list - Automatic residual search for multi-phase identification

- Unique integrated Boolean card retrieval and display

- Single / multi-phase full pattern powder simulations

- Reads common file formats

- Built-in tools include peak finding and background / k- $\alpha_{2}$ stripping

- Report writing directly to Microsoft Word

- Full 32-bit technology delivering unrivalled speed and power

Visit our new web site for details Search-Match? or contact us for a free demo CD!

\section{Upgrade to the state-of-the-art}

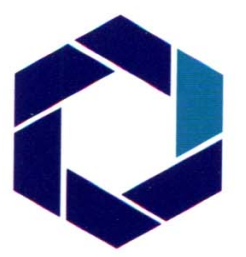

OxfordCryosystems

3 Blenheim Office Park, Lower Road, Long Hanborough Oxford · OX8 8LN - UK

Tel: +44 (0)1993 883488 - Fax: +44(0)1993 883988 E.mail: info@OxfordCryosystems.co.uk 


\section{X-ray diffraction}

\section{for today}

\section{and tomorrow}

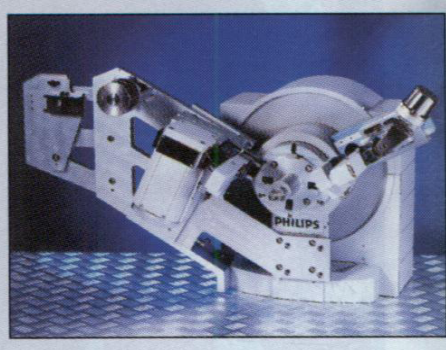

The inevitability of change has long been recognized and the pace of change is accelerating at an ever increasing rate. This is true in the laboratory domain as in every other aspect of modern life. What you require from your X-ray diffractometer could be a world apart from your expectations today.

The Philips X'Pert PRO diffractometer system is an X-ray diffraction system with a virtually limitless capacity to adapt to changing circumstances. the PreFIX (Pre-aligned, Fast-Interchangeable XRay optics) system enables instruments to be reconfigured in a few minutes to handle different types of analysis.

A totally open design architecture guarantees full freedom to accommodate further advances in years to come.

For more information: Philips Analytical Lelyweg 1,7602 EA, Almelo, The Netherlands Tel. : +31 (546) 534444 Fax : +31 (546) 534592 www.analytical.philips.com 
An International Journal of Materials Characterization

Editor-in-Chief

Ting C. Huang

6584 Radko Drive

San Jose, CA 95119-1924 U.S.A.

ting_huang@ibm.net

Managing Editor

Shannon Mattaboni

JCPDS-International Centre for Diffraction Data

12 Campus Blvd.

Newtown Square, PA 19073-3273 U.S.A.

mattaboni@lcdd.com

Editor for Reviews and Reprints

Deane K. Smith

1652 Princeton Drive

State College, PA 16803-3273 U.S.A.

smith@vax1.mrl.psu.edu

Editor for New Diffraction Data

William E. Mayo

Rutgers University

Ceramics Department

Piscataway, NJ 08855-0909 U.S.A.

edisonjam@aol.com

Western European Editor

Norberto Masciocchi

Università di Milano

Dipartimento di Chimica

Strutturale e Stereochimica Inorganica

Via Venezian, 21

20133 Milano, Italy

norbert@csmtbo.mi.cnr.it

Eastern European Editor

Jaroslav Fiala

SKODA Research Ltd.

31600 Plzeñ, Czech Republic

jaroslav.fiala@vsb.cz

Editor for Southeast Asia

Brian H. O'Connor

Curtin University

GPO Box U 1987, Perth 6001

Western Australia, Australia

toconnorb@cc.curtin.edu.au

\section{Editor for Japan}

Hideo Toraya

Ceramics Research Lab

Nagoya Institute of Technology

Asahigaoka, Tajimi 507 Japan

toraya@crl.nitech.ac.jp

International Reports Editor

Winnie Wong- $\mathrm{Ng}$

National Institute of Standards and Technology

100 Bureau Drive Stop 8520

Gaithersburg, MD 20899-8520 U.S.A.

winnie.wong-ng@nist.gov

Editorial Advisory Board

P. Bayliss, Sydney, Australia

C. Z. Bojarski, Katowice, Poland

A. Brown, Dorset, England

D. Cox, Upton, New York

W. Eysel, Heidelberg, Germany

L. Frevel, Midland, Michigan

P. Gado, Budapest, Hungary

H. Goebel, Munchen, Germany

R. Jenkins, Newtown Square, Pennsylvania

G. G. Johnson Jr., State College, Pennsylvania

Q. Johnson, Livermore, California

J. I. Langford, Birmingham, U.K.

D. Louër, Rennes, France

G. J. McCarthy, Fargo, North Dakota

H. F. McMurdie, Gaithersburg, Maryland

M. E. Mrose, Gaithersburg, Maryland

M. Nichols, Livermore, California

R. L. Snyder, Columbus, Ohio

T. Yamanaka, Tokyo, Japan

R. A. Young, Atlanta, Georgia

AlP Production: Lin Miller, Editorial Supervisor Andrea Witt, Journal Coordinator

Kelly Quigley, Chief Production Editor
Powder Diffraction is a quarterly journal published by the JCPDS-International Centre for Diffraction Data through the American Institute of Physics (AIP). Powder Diffraction is a journal of practical technique, publishing articles relating to the widest range of application-from mineral analysis to epitactic growth of thin films and to the latest advances in software. Although practice will be emphasized, theory will not be neglected, especially as its discussion will relate to better understanding of technique.

Submit manuscripts ( 3 copies) to the most appropriate Powder Diffraction Editor listed on this page. The Editors will consider all manuscripts received, but assume no responsibility regarding them. Materials will be returned only when accompanied by appropriate postage. There is no publication charge. See Powder Diffraction Notes for Authors for additional information.

Proofs and all correspondence concerning papers in the process of publication should be addressed to: Editorial Supervisor, Powder Diffraction, AIP, Suite 1NO1, 2 Huntington Quadrangle, Melville, NY 11747-4502.

For advertising rates and schedules contact AIP Advertising Department. Orders, advertising copy, and offset negatives should be sent to: Advertising Department, American Institute of Physics, Suite 1NO1, 2 Huntington Quadrangle, Melville, NY 11747-4502; phone: (516) 576-2440; fax: (516) 576-2481.

\begin{tabular}{|c|c|c|c|c|}
\hline $\begin{array}{l}\text { Subscription } \\
\text { (1999) }\end{array}$ & $\begin{array}{l}\text { Prices } \\
\text { U.S.A \& Canada }\end{array}$ & $\begin{array}{l}\text { Mexico, Central } \\
\text { \& South America }\end{array}$ & $\begin{array}{l}\text { Europe, Mid-East } \\
\qquad \& \text { Africa }^{*}\end{array}$ & $\begin{array}{l}\text { Asia \& } \\
\text { Oceania* }\end{array}$ \\
\hline $\begin{array}{l}\text { Individual } \\
\text { Institutional } \\
\text { or Library }\end{array}$ & $\begin{array}{r}\$ 60 \\
\$ 105\end{array}$ & $\begin{array}{r}\$ 85 \\
\$ 105\end{array}$ & $\begin{array}{r}\$ 85 \\
\$ 105\end{array}$ & $\begin{array}{r}\$ 85 \\
\$ 105\end{array}$ \\
\hline
\end{tabular}

*Subscription rates to Eastern Hemisphere include air freight service.

Back-Number Prices. 1999 single copies: $\$ 30$. Prior to 1999 single copies: $\$ 30$.

Subscription, renewals, and address changes should be addressed to AIP Circulation and Fulfillment Division (CFD), Suite 1NO1, 2 Huntington Quadrangle, Melville, NY 11747-4502. Allow at least six weeks advance notice. For address changes please send both old and new addresses and, if possible, include a mailing label from the wrapper of a recent issue.

Claims, Single Copy Replacement and Back Volumes: Missing issue requests will be honored only if received within six months of publication date (nine months for Australia and Asia). Single copies of a journal may be ordered and back volumes are available in print or microform. Individual subscribers please contact AIP Circulation and Fulfillment Division (CFD) at (516) 576-2288; (800) 344-6901. Institutional or library subscribers please contact AIP Subscriber Services at (516) 576-2270; (800) 344-6902.

Reprint Billing: Contact: AIP Circulation and Fulfillment Division, Melville, NY 117474502; (516) 576-2230; (800) 344-6909.

Copying: Single copies of individual articles may be made for private use or research. Authorization is given (as indicated by the Item Fee Code for this publication) to copy articles beyond the use permitted by Sections 107 and 108 of the U.S. Copyright Law, provided the copying fee of $\$ 6$ per copy per article is paid to the Copyright Clearance Center, 222 Rosewood Drive, Danvers, MA 01923, USA. Persons desiring to photocopy materials for classroom use should contact the CCC Academic Permissions Service. The Item Fee Code for this publication is 0885-7156/96 $\$ 6.00$.

Authorization does not extend to systematic or multiple reproduction, to copying for promotional purposes, to electronic storage or distribution, or to republication in any form. In all such cases, specific written permission from AIP must be obtained.

Permission for Other Use: Permission is granted to quote from the journal with the customary acknowledgment of the source. To reprint a figure, table, or other excerpt requires the consent of one of the authors and notification to AIP.

Requests for Permission: Address requests to AIP Office of Rights and Permissions, Suite 1NO1, 2 Huntington Quadrangle, Melville, NY 11747-4502; Fax: 516-576-2327; Telephone: 516-576-2268; E-mail: rights@ aip.org.

Document Delivery: Copies of journal articles can be ordered for online delivery from the new Articles in Physics online document delivery service (URL: http://www.aip.org/ articles/).

Reprints: Reprints can be ordered with or without covers only in multiples of 50 (with a minimum of 100 in each category) from AIP, Circulation \& Fulfillment/Reprints, Suite 1NO1, 2 Huntington Quadrangle, Melville, NY 11747-4502; Fax: 516-349-9704; Telephone: 800-344-6909 (in U.S. and Canada), or 516-576-2234.

Powder Diffraction (ISSN: 0885-7156) is published quarterly (4X annually) by the JCPDS-International Centre for Diffraction Data through the American Institute of Physics. 1999 Subscription rates: US\$105. POSTMASTER: Send address changes to Powder Diffraction, AIP Circulation \& Fulfillment Division, Suite 1NO1, 2 Huntington Quadrangle, Melville, NY 11747-4502. Periodicals postage paid at Huntington Station, NY 11746, and additional mailing offices.

Online Availability: Abstracts of journal articles published by the AIP and Member Societies (and several other physics publishers) are available in the SPIN database via the AIP online service PINET. Also available on PINET are Advance Abstracts, a current awareness service, other physics information resources, as well as internet services (Internet: elecprod@aip.org).

Copyright 1999 JCPDS-International Centre for Diffraction Data, 12 Campus Bhud., Newtown Square, PA 19073-3273. All rights reserved.

www.icdd.com/products/journals.htm 

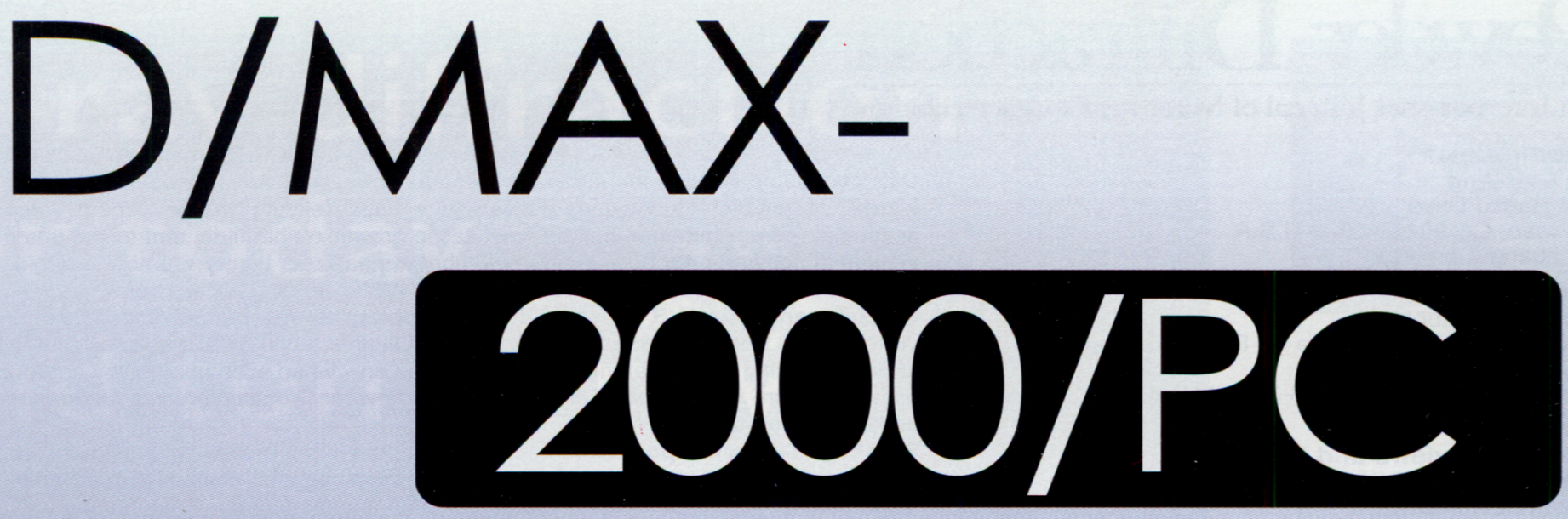

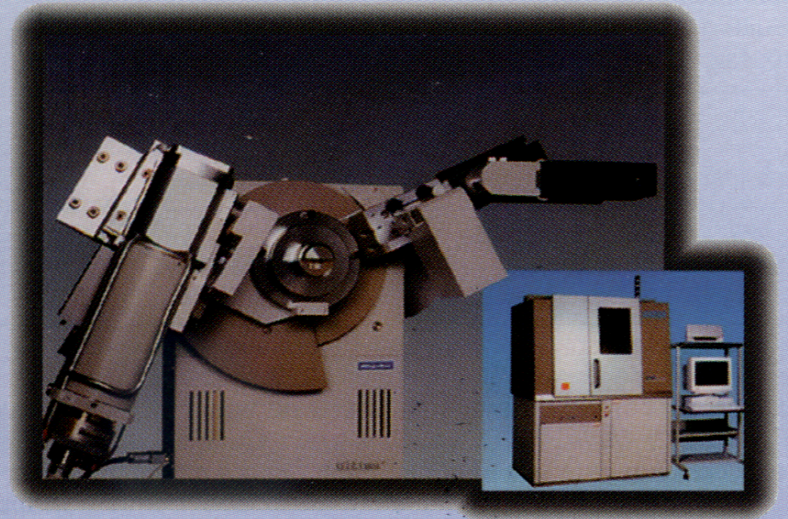

- Standard features provide the most flexibility for your investment

- Flexible optical system

- User-friendly software and hardware

- Attachments for every application

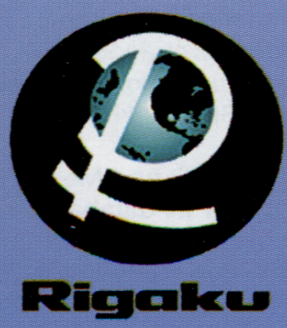

North America:

9009 New Trails Drive The Woodlands,

Texas 77381 USA

Tel: $281-367-2685$

Fax: $281-364-3628$

e-mail: info@rigaku.com http://www.rigaku.com/
Rigaku's D/MAX family of x-ray diffractometers continues to evolve with the 2000/PC.

The D/MAX-2000/PC includes focusing and parallel-beam optics, which can be exchanged by the user in half a minute without realignment.

Variable slits are standard, providing exceptional low-angle performance down to $1.5^{\circ}$, a real benefit for many pharmaceutical and geological applications.

Rigaku's graphite diffracted-beam monochromator is specially designed for both focusing and parallel-beam configurations no need for additional hardware and timeconsuming reconfiguration.

In addition, the D/MAX-2000/PC offers the highest degree of automation found in any diffraction system.

Whether you require sealed-tube sources, high-reliability rotating anodes, or mirror optics, Rigaku has it all.

Japan:

3-9-12 Matsubara-cho, Akishima-shi, Tokyo 196-8666, Japan

Tel: $81-42-545-8189$

Fax: $81-42-545-7985$

e-mail: rinttyo@rigaku.co.jp Telex: J26418 RINT 
Ting C. Huang

J. A. Kaduk

Lj. Karanović,

I. Petrović-Prelević, and D. Poleti

W. Wong-Ng, J. A. Kaduk, R. A. Young, F. Jiang,

L. J. Swartzendruber, and H. J. Brown

Gilberto Artioli, Maurizio Marchi

J. M. S. Skakle, R. Herd

Tonči Balić Žunić, Jesper Dohrup

Giorgio Spinolo, Filippo Maglia

W. Pitschke, K. Koumoto

V. Venegas, A. Gómeż, and E. Reguera

F. Lucas, A. Elfakir, and M. Quarton

Raj P. Singh, Michael J. Miller, and Jeffrey N. Dann

M. Touboul, N. Pénin, and L. Seguin

M. Touboul, N. Penin, and L. Seguin
Editorial: New International Reports Editor and Managing Editor

165

Combining CDIF and PDF information in problem solving: Crystal structure

166 of a corrosion deposit, hexaaquairon(II) trifluoromethanesulfonate

A practical approach to Rietveld analysis. Comparison of some programs running on personal computers

Investigation of $\left(\mathrm{Sr}_{4-\delta} \mathrm{Ca}_{\delta}\right) \mathrm{PtO}_{6}$ using $\mathrm{X}$-ray Rietveld refinement

On the space group of garronite

190

Crystal chemistry of (RE,A) ${ }_{2} \mathrm{M}_{3} \mathrm{O}_{7}$ compounds ( $\mathrm{RE}=\mathrm{Y}$, lanthanide; $\mathrm{A}=\mathrm{Ba}$, $\mathrm{Sr}, \mathrm{Ca} ; \mathrm{M}=\mathrm{Al}, \mathrm{Ga}$ )

Use of an ellipsoid model for the determination of average crystallite shape and size in polycrystalline

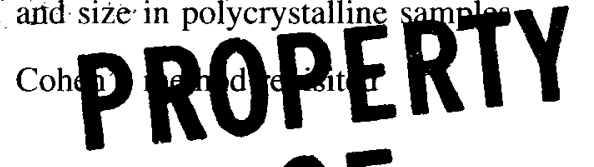

Powder diffraction $\mathrm{A}_{4}$ a and Rietveld refinement for $\mathrm{Y}$-doped $(\mathrm{ZnO})_{5} \mathrm{In}_{2} \mathrm{O}_{3}$

Powder X-ray diffraction study of disilver $\left(1^{+}\right)$

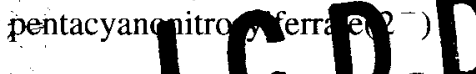

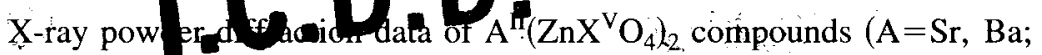

$\mathrm{X}=\mathrm{P}, \mathrm{As})$

X-ray diffraction analysis of $\left(\mathrm{Na}_{0.6} \mathrm{H}_{0.4}\right)\left(\mathrm{Ta}_{0.7} \mathrm{Nb}_{0.2}\right) \mathrm{O}_{3}$

$\mathrm{Tl}\left[\mathrm{B}_{5} \mathrm{O}_{6}(\mathrm{OH})_{4}\right] \cdot 2 \mathrm{H}_{2} \mathrm{O}$ and $\mathrm{TlB}_{5} \mathrm{O}_{8}$

$\begin{array}{ll}\text { International Reports } & 240 \\ \text { Regional Report } & 240\end{array}$

A Farewell and Introduction $\quad 241$

Calendar of Meetings $\quad 241$

Short Courses \& Workshops $\quad 245$

Cumulative Author Index 


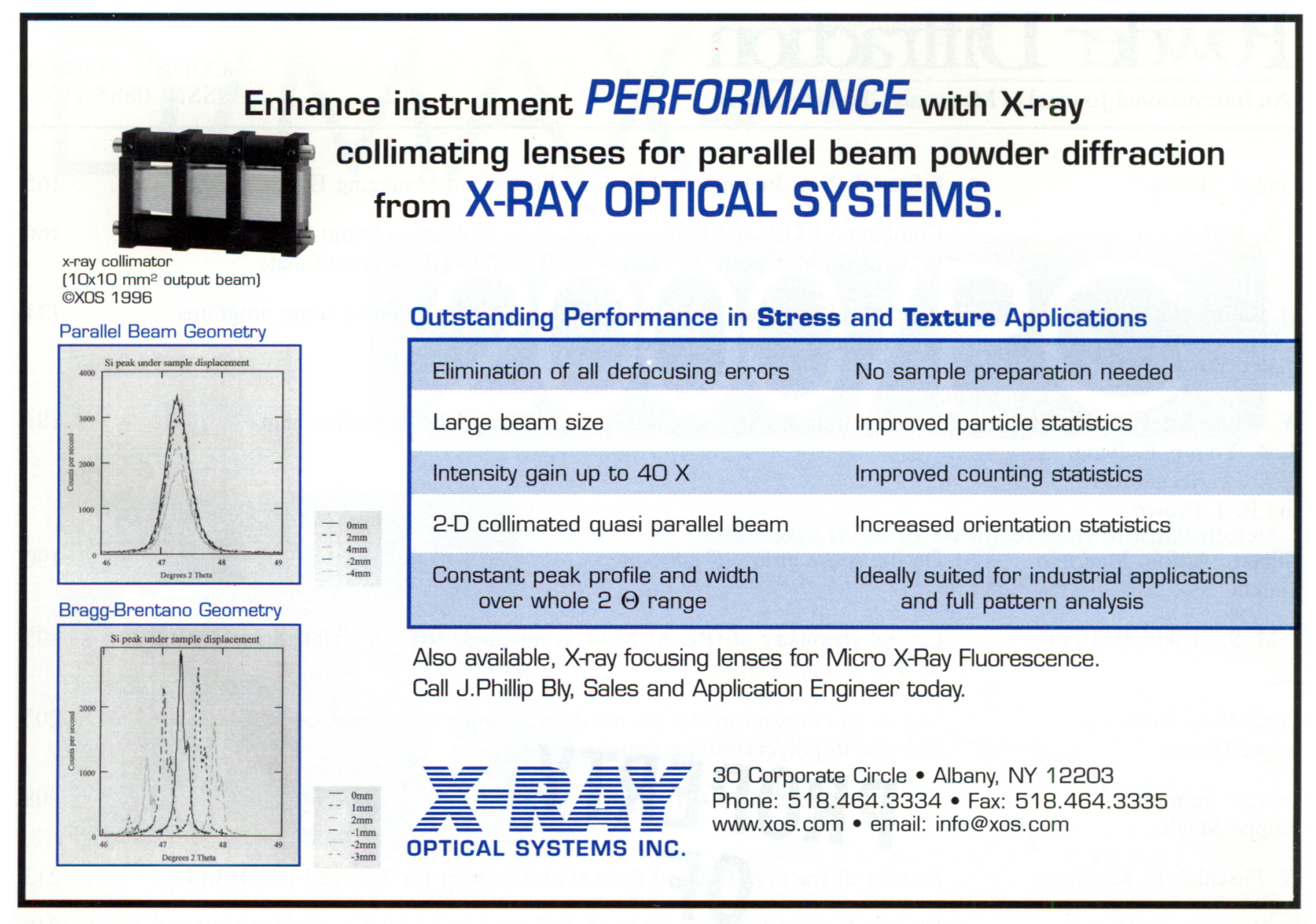

\section{(Hinel REAL TIME XRD}

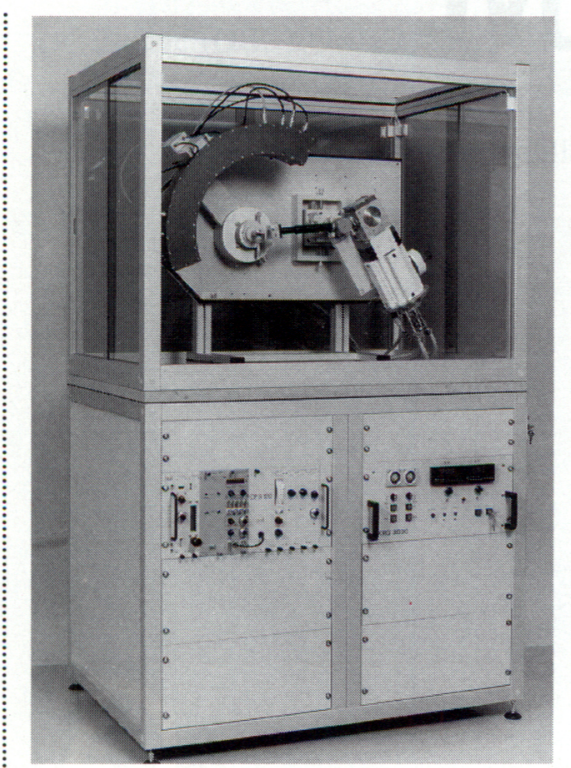

MPD Multi-Purpose X-ray Diffractometer
Versatile diffractometers designed to take advantage of the rapid, real time data collection our patented CPS X-ray detectors offer.

${ }^{*}$ No scanning feature - acquire up to $120^{\circ} 2 \theta$ simultaneously

-Unique capillary devices for analysis of air sensitive materials -Identify materials even if only micro amounts are available -Parallel beam with germanium or multilayer mirror optics for information on our complete product line please contact us

inel - Z.A - CD 405 - 45410 ARTENAY (FRANCE)

Tel. (33) 0238804545 Fax. (33) 0238800814

E.MAIL: inel@valcofim.fr-INTERNET:http://www.valcofim.fr/inel

inel Inc. P.O. Box 147, STRATHAM, NH 03885 (USA)

TEL. (603) 778-9161 FAX. (603) 778-9171

E-MAIL: inelinc@aol.com 


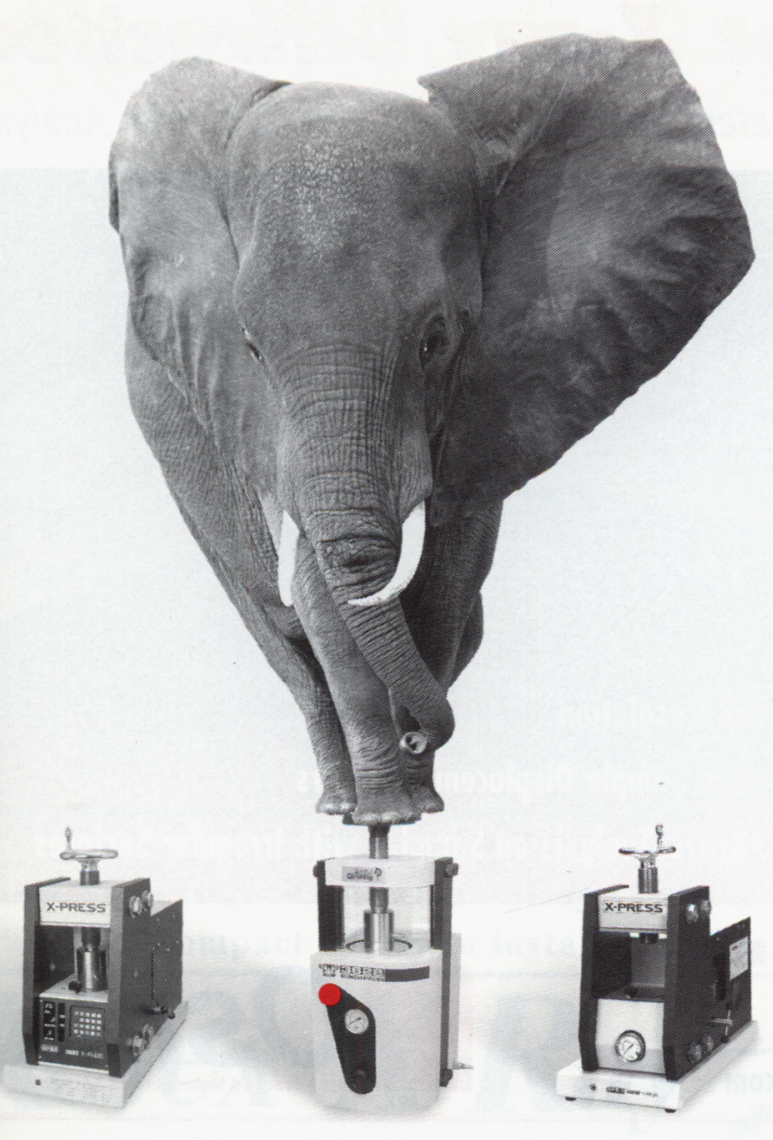

\section{Performs Great Under Pressure}

SPEX CertiPrep introduces a unique manual press which performs with the greatest of ease! Try one out today and start reducing your sample pelletizing costs to mere peanuts a day!

The Air-actuated Bench-Press ${ }^{\mathrm{TM}}$ eliminates the tedious task of hand pumping, necessary with other manual presses. Just push the button and the Bench-Press will generate up to 25 Tons of pressure for sample pelletizing.

SPEX CertiPrep also offers the X-Press Series of 35 ton, automated laboratory presses, the 3630 and the 3624B.

A variety of pellet dies, reinforcing caps (SPEC-Caps), and Prep-Aid ${ }^{\mathrm{TM}}$ (sample binder) are also available to meet all of your sample pelletizing needs.

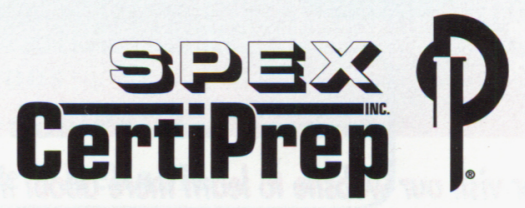

203 Norcross Avenue Metuchen, NJ 08840

Website: www.spexcsp.com Phone: $\quad$ 732-549-7144 Fax: $\quad$ 732-603-9647

1-800-LAB-SPEX • sampleprep@spexcsp.com (e-mail)

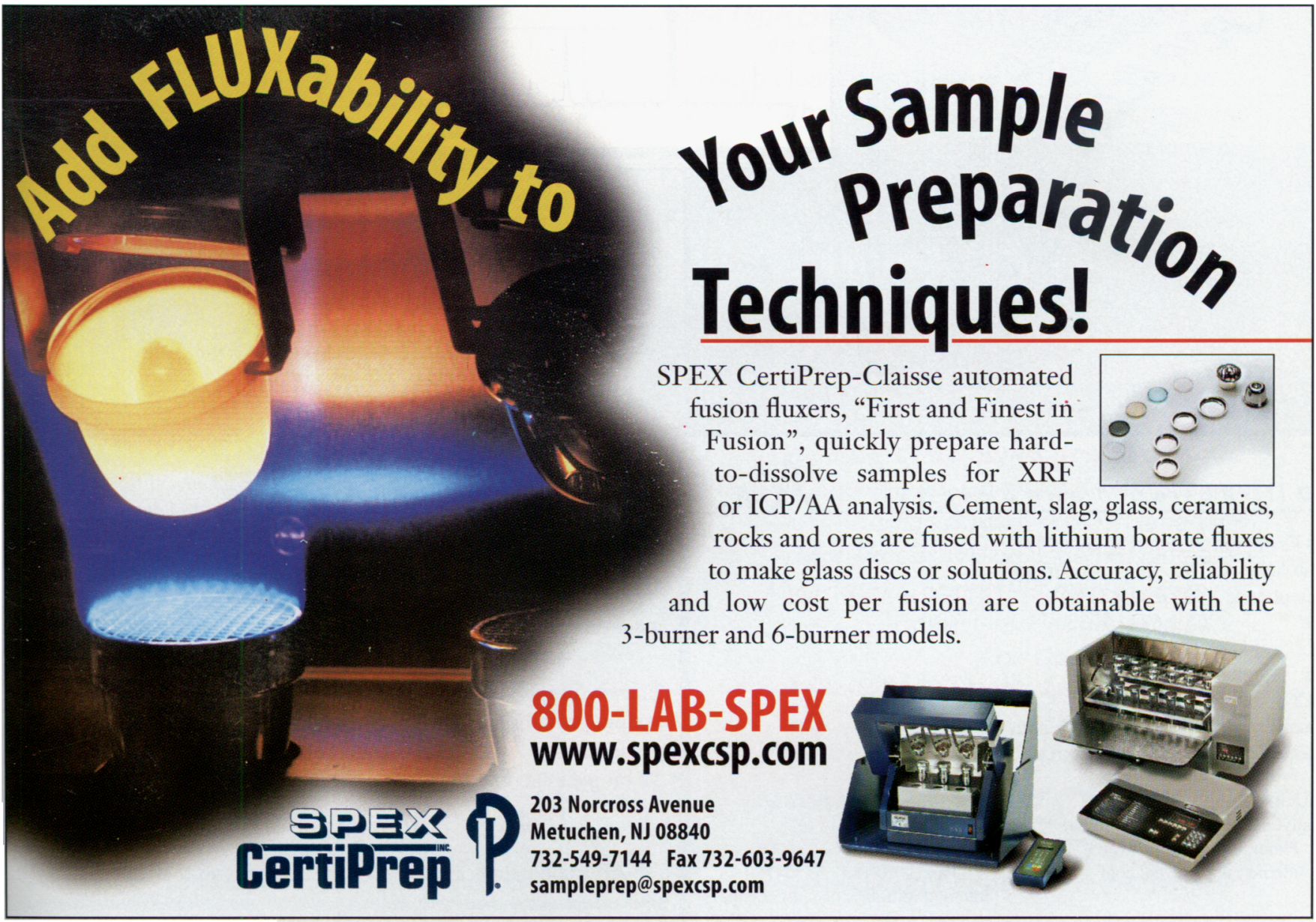




\section{Diffraction Technology}
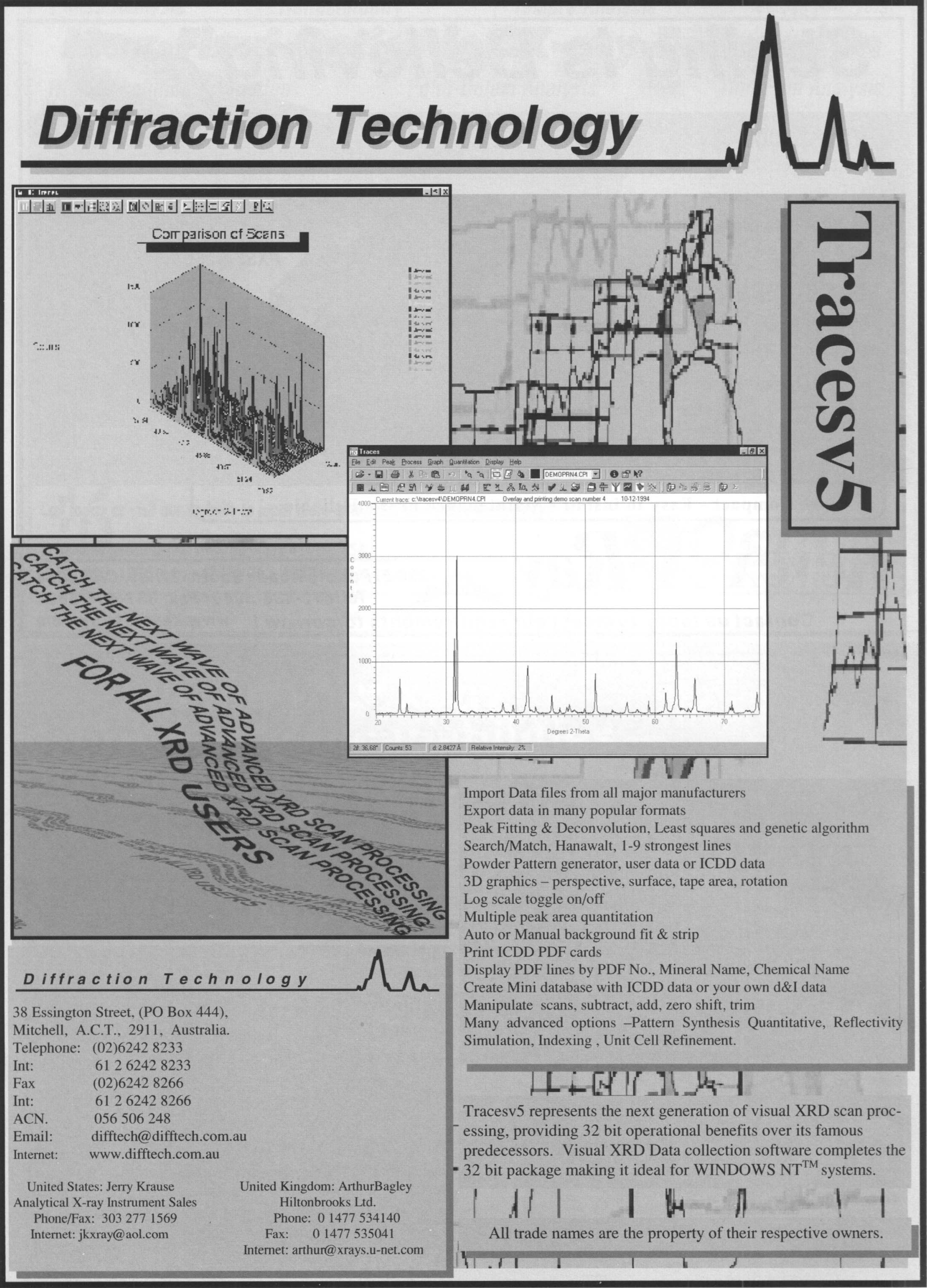


\section{Kratos/SHIMadzU X-RaY Laboratory Powerful technologies for elemental analysis Solids, Llavids, Powders \& Wafers \\ (1)}

\section{EDXRF}

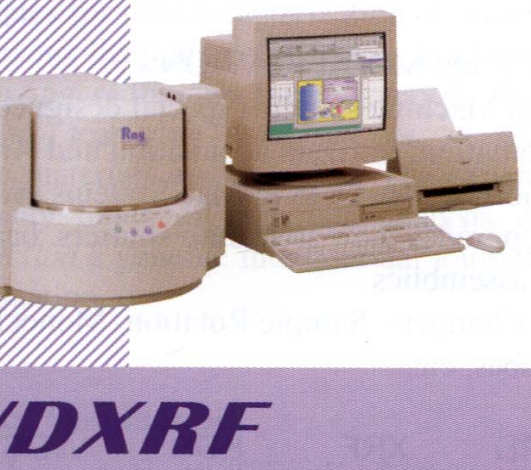

\section{WDXRF}

\section{Explore the New}

EDX-800

ENERGY DISPERSIVE X-RAY FLUORESCENCE SPECTROMETER

Simple, Powerful Performance..

Simultaneous Measurement of Carbon to Uranium With $A$ Touch of a Button 300MM Wafer Handling Facilities Analysis in Helium, Vacuum or Air

Fully Automated Measurements Local Area Analysis with Scanning Standardless Fundamental Parameters Large Chamber with Automated Open/Close

$X R F-1700$

SEQUENTAL X-RAY FLUORESCENCE SPECTROMETER The Only Imaging Wavelength Dispersive Instrument in the World.. Ultra High Performance, Speed and Versatility for Qualitative \& Quantitative Analysis Rapid Qualitative Analysis of Elements Be to $U$ $1 \mathrm{~mm}$ Local Area Analysis with Mapping $30 \mathrm{~mm}$ Wide Area Analysis Reliable Determination of $C, H \& O$ Quantitative Data from RhKa Scattering \& FP Methods Ultra High Resolution, Sensitivity \& Accuracy Simple, Powerful Multi-Tasking Operation

\section{$X \boldsymbol{R} D$}

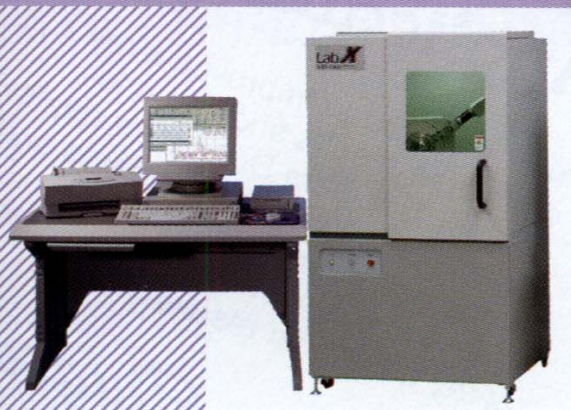

XRD -6000

PRECISION ENGINEERED X-RAY DIFFRACTION SYSTEM Fast \& Accurate Identification \& Quantification Of

Crystalline Compounds and Structures Precision Engineered, Compact X-Ray System High Stability X-Ray Generator High Precision/High Speed Goniometer Multi-Tasking Support/Parallel Processing Consistent, Reliable Operation Low Cost of Ownership Ask about our new applications booklet on solid state pharmaceutical products
Q ail o. Wan for more information: PHon E: 9) 4) 426-6700 FAX: (914)426-6192

E-Mall: info@kratos.com huTERNET: http://www.kratos.com

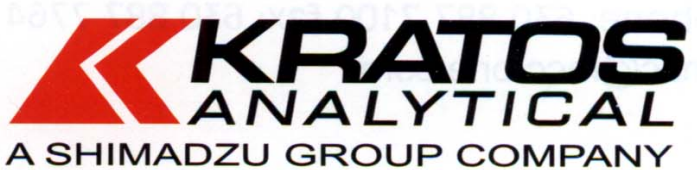




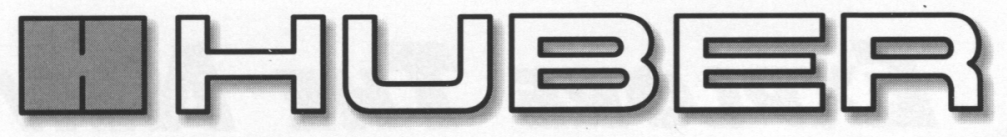

\section{Power in Powder Diffraction!}

\section{IMAGE FOIL \\ GUINIER CAMERA 670}

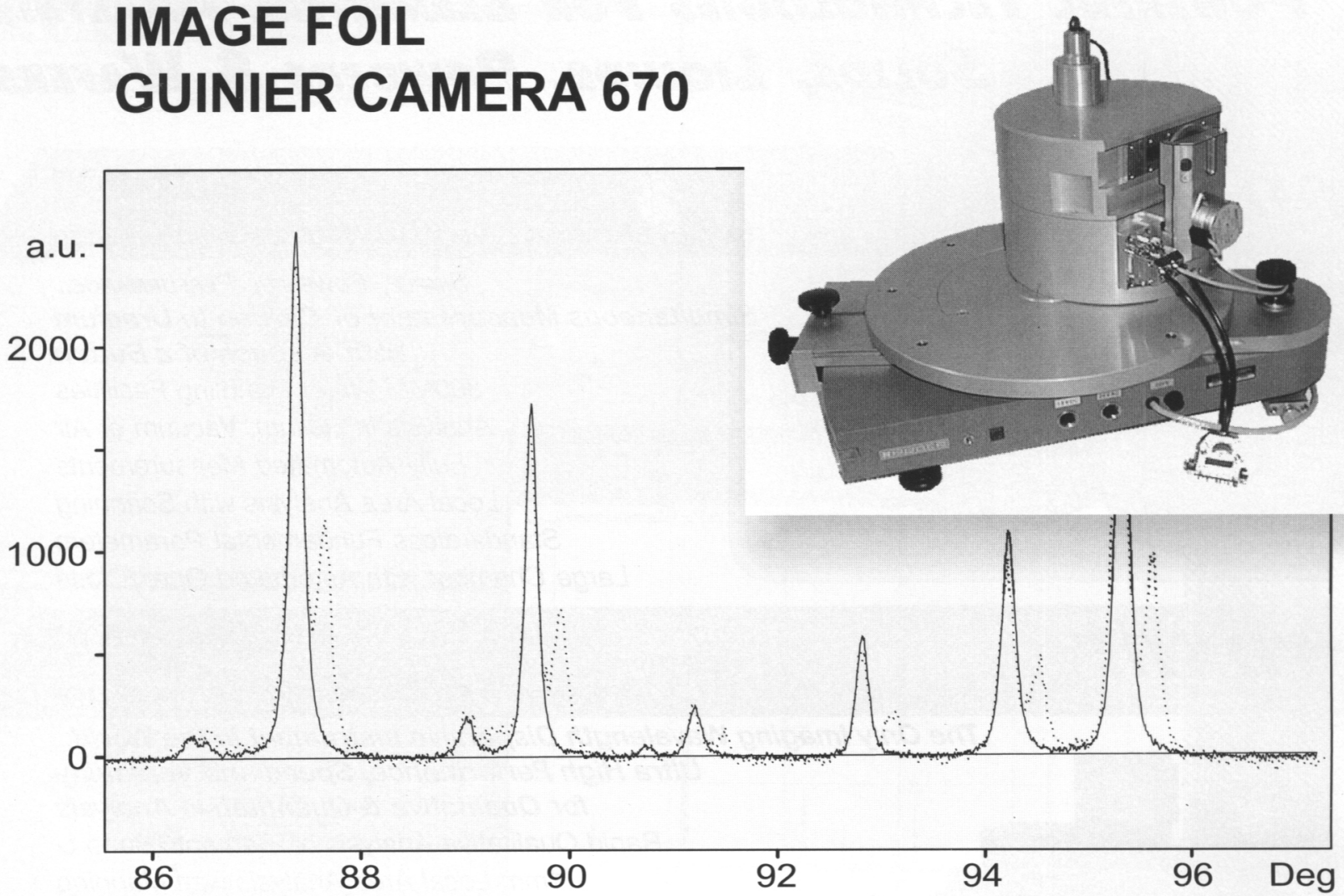

Get your diffractogram data within a couple of minutes! And get them without those bulky $\mathrm{K} \alpha_{2}$ peaks.

Just have a look at the scan above. This is a zoomed view of sample $1 \mathrm{~g}$ of the Commission on Powder Diffraction - Round Robin 1998. The dotted line was scanned on a conventional Bragg-Brentano instrument. It took some 4 hours for $100^{\circ} 2$-Theta with 3 sec per $0.02^{\circ}$ step. The unbroken line results from our $\mathrm{G} 670$ and took 30 minutes for the same scan range but with $0.005^{\circ}$ step size. Not to mention that $\mathrm{K}_{2}$ is obsolete.
The samples are outside of the closed, and thus evacuable, camera housing. The Guinier Camera 670 fits onto the Basis 601 and uses any of the Guinier Monochromators of the HUBER Series 611/15. There are options for the Flat Specimen Sample Oscillation Device 670.1, or for the Capillary Rotation Device 670.2 together with the Furnace 670.3 and the High Temperature Controller 9634. The system includes the data collection software running on a PC. Data files of various popular ASCII types are available for further handling.

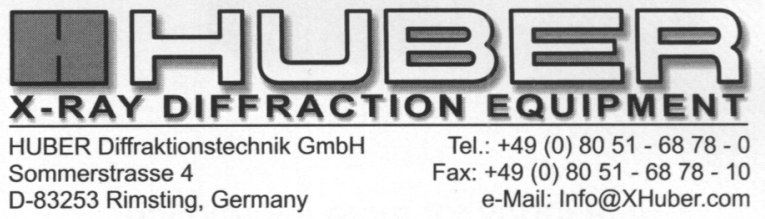




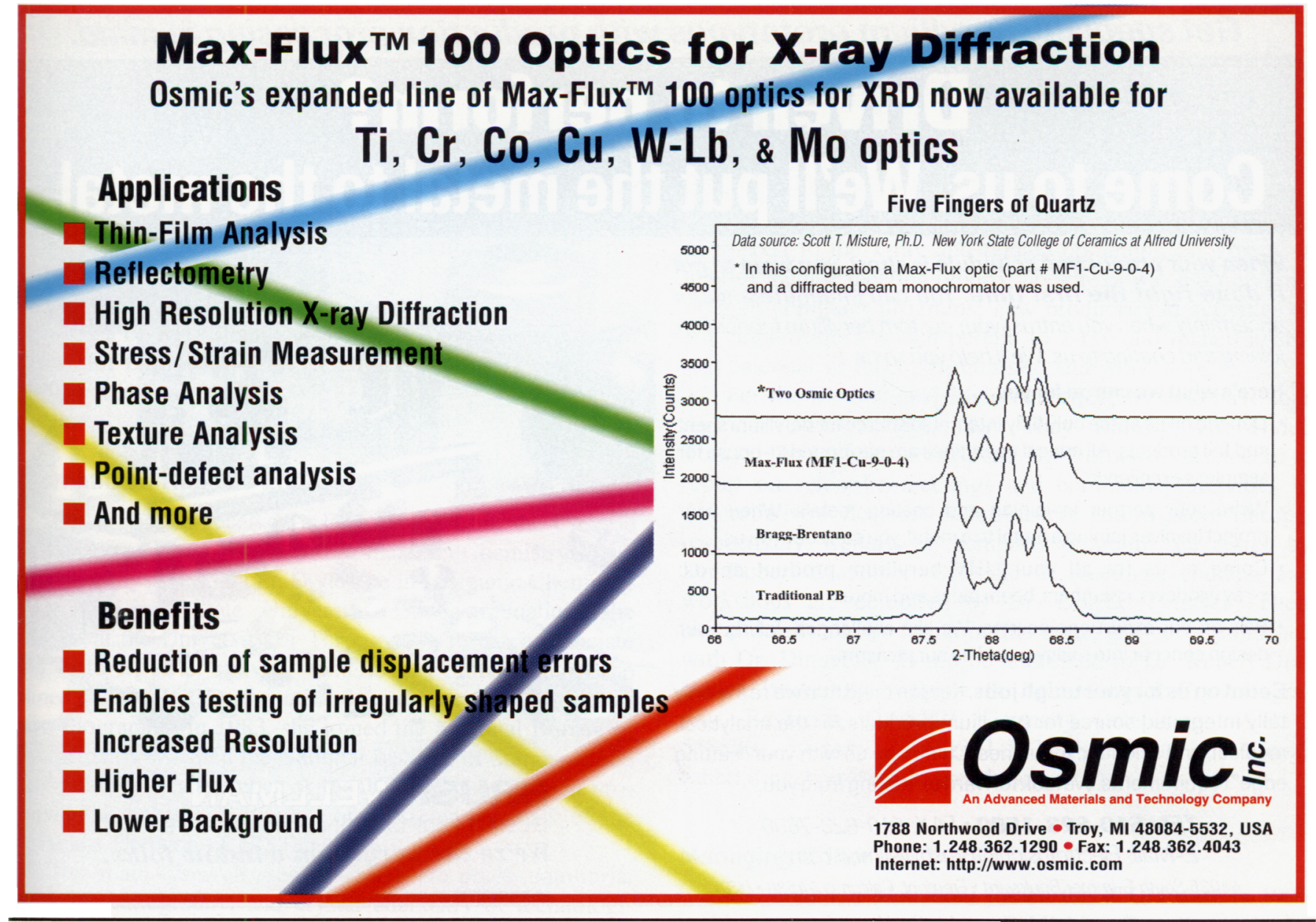

\section{Your Software For X-Ray Analysis}

Now optimized for the new, enhanced PDF database with more than 37,000 additional calculated patterns

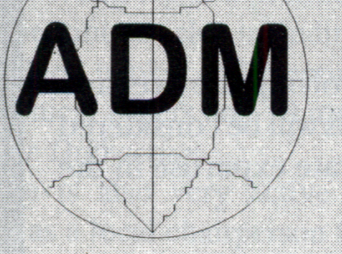

PADS

New Edition
Software package for data aquisition and analysis:

Diffractometer control, plot modules, peak search and calibration, qualitative and quantitative phase analysis, profile fitting and pattern simulation, lattice parameter refinement, crystallite size and micro stress.

Ready to plug to your PHILIPS and SIEMENS diffractometer hardware.

Stand alone package for qualitative and quantitative phase analysis.

Extremely fast search algorithms for ICDD-PDF database and user created databases. Very exact quantitative analysis using the WHOLE PATTERN method.

Extension package for most third party X-ray software. Graphicanalytical, profile-analytical and crystallographic options. 


\section{Get specialty beryllium prototypes with production processing in mind. Driven to perform? Come to us. We'll put the metal to the metal.}

When your production schedule is short, you want to get it done right the first time. You can eliminate a major uncertainty when you entrust your custom beryllium fabrication, joining and coating to us. We'll help you shine.

Here's what we can do for you:

- Depend on us as the only fully integrated source for beryllium sheet and foil products. All critical operations are performed in-house for seamless excellence.

- We're your partner in joining and coating metals. When your project involves joining a metal to a metal, you can count on us.

- Come to us for all your UHV beryllium product needs: $x$-ray windows, chambers, beam pipes and more.

- Rely on our expert engineering. We like challenges. Taking your design concept into reality would be our pleasure.

Count on us for yourtough jobs. Keep in mind that we're the only fully integrated source for beryllium products for the analytical, medical, and scientific industries. Challenge us with your "cutting edge" requirements. We look forward to hearing from you.

TEL: 510-623-1500 • FAX: 510-623-7600

E-Mail: Electrofusion@BrushWellman.com

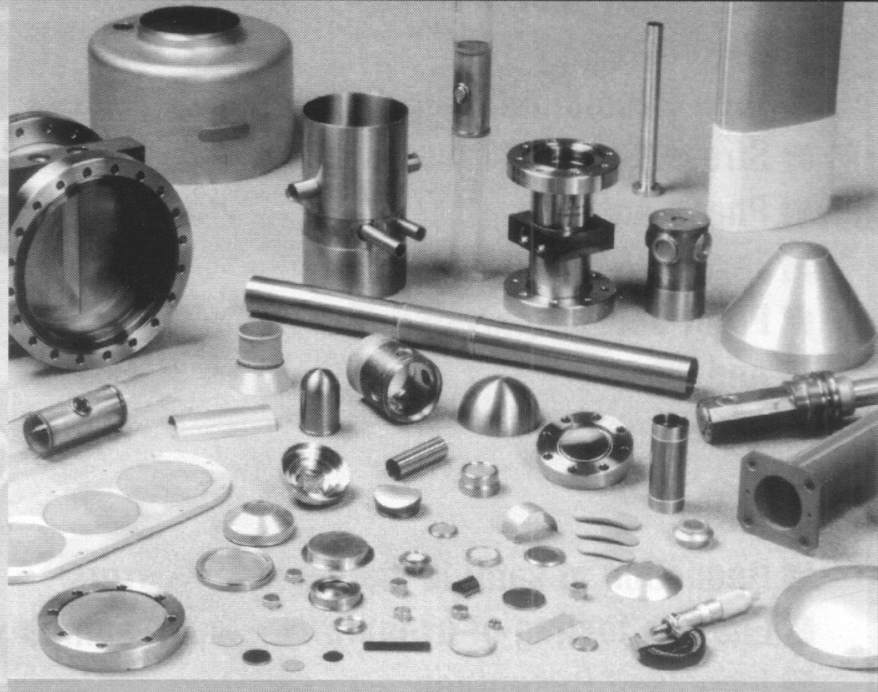

BRUSHWLLLMAN

ELECTROFUSIONPRODUCTS

We're the beryllium window folks.

44036 South Grimmer Boulevard • Fremont, California 94538 • USA

\section{ICDD's Grant-in-Aid Program}

The International Centre for Diffraction Data (ICDD) is interested in high quality experimental powder diffraction patterns to add to its internationally renowned database, the Powder Diffraction File ${ }^{\mathrm{TM}}$ $\left(\mathrm{PDF}^{\circledast}\right)$. The ICDD Grant-in-Aid Program is designed to give limited financial support to those institutions interested in supplying new patterns.

A grant can be used most effectively as supplement to existing funded projects involving the preparation and characterization of new materials, using powder XRD. Grant-in-Aid proposals will be considered on a worldwide competitive basis from any qualified investigator who can demonstrate expertise in the preparation of high quality powder diffraction patterns.

There are two grant cycles with proposal deadlines of:

$\begin{array}{ll}\text { Cycle I } & \text { 31 January } \\ \text { Cycle II } & \text { 31 July }\end{array}$

The duration of a grant is 12 months. Recipients are required to submit biannual progress reports and must reapply every year if they wish to be considered for renewal.

For more information, please review the guidelines found at ICDD's web site, http://www.icdd.com, or contact the ICDD's Data Acquisition Manager:

Ms. Therese Mauchline

International Centre for Diffraction Data

12 Campus Boulevard

Newtown Square, PA 19073-3273 U.S.A.
Telephone: (610) 325-9814

Fax: (610) 325-9823

E-mail: MAUCHLINE@ICDD.COM 